\title{
TOLERÂNCIA DE MAMONA A ZINCO AVALIADA POR FLUORESCÊNCIA DE CLOROFILA E NUTRIÇÃO DAS PLANTAS $^{(1)}$
}

\author{
Marise Conceição Marques ${ }^{(2)}$ \& Clístenes Williams Araújo do Nascimento(3)
}

\begin{abstract}
RESUMO
A medida da fluorescência de clorofila pode ser uma ferramenta útil para detectar alterações no aparato fotossintético das plantas. Considerando que a detecção precoce da contaminação de zinco em plantas é essencial para o monitoramento ambiental, este trabalho objetivou avaliar o estresse causado por esse nutriente em plantas de mamona (Ricinus communis), utilizando a técnica da fluorescência de clorofila. As alterações provocadas pelo $\mathrm{Zn}$ nos pigmentos fotossintéticos e na composição mineral das plantas foram também estudadas. Plantas de mamona foram cultivadas durante 28 dias em solução nutritiva com cinco doses de $\mathrm{Zn}\left(100,200,300,400\right.$ e $\left.600 \mu \mathrm{mol} \mathrm{L}^{-1}\right)$, além de um controle contendo $0,380 \mu \mathrm{mol} \mathrm{L} \mathrm{L}^{-1}$ do elemento. A fluorescência de clorofila detectou alterações temporais promovidas pelo acúmulo de $\mathrm{Zn}$ nas plantas e evidenciou-se útil na deteç̧ão precoce da toxicidade do elemento em plantas de mamona. Apesar do declínio no seu estado nutricional, a mamona apresentou relativa tolerância à toxicidade a doses elevadas de $\mathrm{Zn}$, indicando ser essa espécie uma alternativa atraente para revegetação ou remediação de áreas contaminadas.
\end{abstract}

Termos de indexação: Ricinus communis, elemento-traço, poluição do solo, fotossintese.

\section{SUMMARY: TOLERANCE OF CASTOR BEAN TO ZINC ASSESSED BY CHLOROPHYLL FLUORESCENCE AND PLANT NUTRITION}

Measurement of chlorophyll fluorescence can be a useful tool for detecting changes in the photosynthetic apparatus of plants. With the understanding that early detection of zinc $(\mathrm{Zn})$ contamination is fundamental in environmental monitoring, the aim of this study was to

\footnotetext{
(1) Parte da Tese do Doutorado da primeira autora, apresentada ao Programa de Pós-Graduação em Ciência do Solo da Universidade Federal Rural de Pernambuco - UFRPE. Recebido para publicação em 26 de abril de 2013 e aprovado em 13 de janeiro de 2014.

(2) Doutora em Ciência do Solo, Programa de Pós-Graduação em Ciência do Solo, UFRPE. R. Dom Manoel de Medeiros, s/n, Dois Irmãos. CEP 52171-900 Recife (PE). E-mail: mcmarques12@hotmail.com

(3) Professor Associado, Departamento de Agronomia, UFRPE. Bolsista de produtividade do CNPq. E-mail: clistenes@depa.ufrpe.br
} 


\begin{abstract}
assess Zn stress in castor bean (Ricinus communis) plants using X-ray chlorophyll fluorescence. The changes brought about by $\mathrm{Zn}$ in photosynthetic pigments and in the mineral composition of plants were also studied. Castor bean plants were grown for 28 days in a nutrient solution with five $Z n$ rates $\left(100,200,300,400\right.$, and $\left.600 \mu \mathrm{mol} \mathrm{L} \mathrm{L}^{-1}\right)$, as well as a control with 0.380 $\mu \mathrm{mol} \mathrm{L} \mathrm{L}^{-1}$ of $\mathrm{Zn}$. Chlorophyll fluorescence detected temporal changes from $\mathrm{Zn}$ accumulation in plants and proved to be useful in early detection of $Z n$ toxicity in castor bean. Despite negative effects on nutritional status, castor bean was relatively tolerant to Zn toxicity, indicating that the species is an attractive alternative for revegetation or remediation of $\mathrm{Zn}$ contaminated areas.
\end{abstract}

Index terms: Ricinus communis, trace elements, soil pollution, photosynthesis.

\section{INTRODUÇÃO}

O Zn desempenha importantes funções metabólicas nas plantas. Além de ser associado ao metabolismo de carboidratos, executa papel estrutural ou catalítico em várias enzimas, como a superóxido dismutase, desidrogenase, protease, peptidase e fosfohidrolase (Cherif et al., 2011). Entretanto, quando sua concentração na planta excede níveis ótimos, observase diminuição do crescimento, inibição do desenvolvimento radicular e clorose em folhas (Cunha et al., 2008; Lin \& Aarts, 2012). O aumento das atividades industriais e de mineração, aliado ao uso inadequado de fertilizantes e pesticidas, tem contribuído para elevação dos teores de $\mathrm{Zn}$ no solo (Soares et al., 2001; Cunha et al., 2008).

A toxicidade por $\mathrm{Zn}$ pode induzir a produção de espécies reativas de oxigênio, como superóxido $\left(\mathrm{O}_{2}{ }^{-}\right)$, radicais hidroxila $\left(\mathrm{OH}^{-}\right)$e peróxido de hidrogênio $\left(\mathrm{H}_{2} \mathrm{O}_{2}\right)$, que, ao interagirem com componentes celulares, promovem danos oxidativos em ácidos nucleicos, proteínas, açúcares e lipídios. Tais danos levam ao estresse oxidativo em células e membranas $\mathrm{e}$, em condições extremas, à morte celular (Gadjev et al., 2008). O estresse por Zn é também responsável por alterações no aparato fotossintético. Cambrollé et al. (2013) observaram que doses de Zn acima de 90 $\mathrm{mmol} \mathrm{L}{ }^{-1}$ foram responsáveis pelo declínio na atividade fotossintética, resultando em decréscimo na concentração de pigmentos em Limoniastrum monopetalum (L.).

Existem cerca de 250 a 400 moléculas de clorofilas $(a$ e $b$ ) e carotenoides incorporadas nas unidades dos fotossistemas, as quais se localizam nas membranas dos tilacoides dos cloroplastos. Há dois tipos de fotossistemas, PSI e PSII; a principal diferença entre esses é o pico máximo de absorção, de 700 e 680 ๆm, respectivamente. Cada fotossistema apresenta dois componentes: um complexo de antena, responsável pela interceptação da luz; e um centro de reações (Shabala, 2009).

Após um pigmento absorver um fóton, há a possibilidade de transição de um elétron a um nível eletrônico mais elevado, levando à dissipação do excesso de energia, que ocorre mediante emissão de fluorescência. A fluorescência de clorofila é caracterizada por um pico máximo na região vermelha (680-700 ๆm), que é atribuído ao PSII; e outro na região vermelha distante (730-740 $\eta \mathrm{m})$, correspondente ao PSI. Essa fluorescência pode ser uma ferramenta potencial para avaliar a contaminação em ecossistemas causada por metais pesados em plantas, pois consegue detectar alterações no aparato fotossintético (Corcoll et al., 2011; Silva et al., 2012). Essa técnica é não invasiva e pode revelar alterações nas membranas dos cloroplastos resultantes do funcionamento anormal do aparato bioquímico (Joshi \& Mohanty, 2004).

Dessa forma, a detecção precoce da contaminação de Zn em plantas é essencial para o monitoramento ambiental, bem como o potencial da mamona para revegetação de áreas contaminadas por metais e seu concomitante uso para produção de bioenergia. Este trabalho teve o objetivo de avaliar o estresse causado pelo metal em plantas de mamona, utilizando a técnica não invasiva da fluorescência de clorofila e as alterações provocadas pelo $\mathrm{Zn}$ nos pigmentos fotossintéticos e na composição mineral das plantas.

\section{MATERIAL E MÉTODOS}

Sementes de mamona (Ricinus communis cv. BRS Energia) foram germinadas em bandejas contendo vermiculita umedecida com solução de Ca $0,67 \mathrm{mmol} \mathrm{L}^{-1}$, na forma de $\mathrm{Ca}\left(\mathrm{NO}_{3}\right)_{2} 4 \mathrm{H}_{2} \mathrm{O}$. Treze dias após o semeio, plântulas foram selecionadas quanto à homogeneidade e transferidas para vasos plásticos que continham 6 L de solução nutritiva (Hoagland \& Arnon, 1950), com 105,$05 ; 15,5 ; 117,3 ; 100,2 ; 24,3 ; 32,1 ; 0,325 ; 0,25$; 0,$025 ; 0,01 ; 0,25 ; 0,005$; e 7,53 $\mathrm{mg} \mathrm{L}^{-1}$ de N, P, K, Ca, $\mathrm{Mg}, \mathrm{S}, \mathrm{Cl}, \mathrm{Mn}, \mathrm{Zn}, \mathrm{Cu}, \mathrm{B}$, Mo e Fe, respectivamente, a qual foi substituída semanalmente. $\mathrm{O}$ pH da solução foi ajustado sempre que necessário, para valores próximos de 5,6 $\pm 0,2$. Após 14 dias de cultivo, foram acrescentadas na solução doses de 100, 200, 300, 400 e $600 \mu \mathrm{mol} \mathrm{L}-1$ de $\mathrm{Zn}\left(\mathrm{ZnSO}_{4} \cdot 7 \mathrm{H}_{2} \mathrm{O}\right)$, que se configuraram nos tratamentos. Adotou-se um controle, contendo $0,380 \mu \mathrm{mol} \mathrm{L}^{-1} \mathrm{de} \mathrm{Zn}$, equivalente à concentração original do elemento na solução de Hoagland $\left(0,025 \mathrm{mg} \mathrm{L}^{-1}\right)$. Após a adição dos tratamentos, as plantas foram mantidas em casa de vegetação por 28 dias, período suficiente para diferenças visuais no desenvolvimento das plantas em razão dos tratamentos. Posterior a esse período, procedeu-se à coleta e lavagem com água destilada das 
folhas, do caule e das raízes. Esses materiais foram acondicionados em sacos de papel, secos em estufa a 65 ${ }^{\circ} \mathrm{C}$ e tiveram as matérias secas deles determinadas.

A digestão do material vegetal, seco e triturado em moinho tipo Willey, foi efetuada em ácidos nítrico e clorídrico, em forno de micro-ondas (Mars Xpress), segundo o método 3051A (USEPA, 1998). Esse material também foi submetido à digestão sulfúrica para determinação de N. Foram determinados os teores de $\mathrm{Zn}$ e $\mathrm{Cu}$, por espectrofotometria de absorção atômica (AAnalyst 800); e os de Ca, Mg, Fe, Mn, Mo e B, por espectrometria de emissão ótica (ICP-OES/Optima 7000, Perkin Elmer). Os teores de N, K e P foram determinados por titulometria, fotometria e colorimetria, respectivamente. Para avaliação da qualidade das análises para $\mathrm{Zn}$, foi utilizado um padrão do National Institute of Standards and Technology (1570a-Trace elements in spinach), sendo obtida uma recuperação de $98 \%$ de Zn do padrão adicionado.

As medidas de fluorescência de clorofila foram efetuadas com um emissor de luz ultravioleta LED, com picos de comprimento de onda vermelho (685 $\eta \mathrm{m})$ e vermelho distante (735 $\eta \mathrm{m})$, obtidos pelo software do aparelho (Ocean Optics-Spectra Suite). Efetuaramse quatro avaliações ao longo do experimento. A primeira medida foi tomada antes da adição do Zn; e a última, um dia antes da coleta das plantas. Essas avaliações foram realizadas à noite a partir da permanência das plantas por 20 min no escuro, com o intuito de garantir a desativação do transporte de elétrons da fotossíntese. As medidas foram efetuadas no segundo par de folhas abaixo do meristema apical,
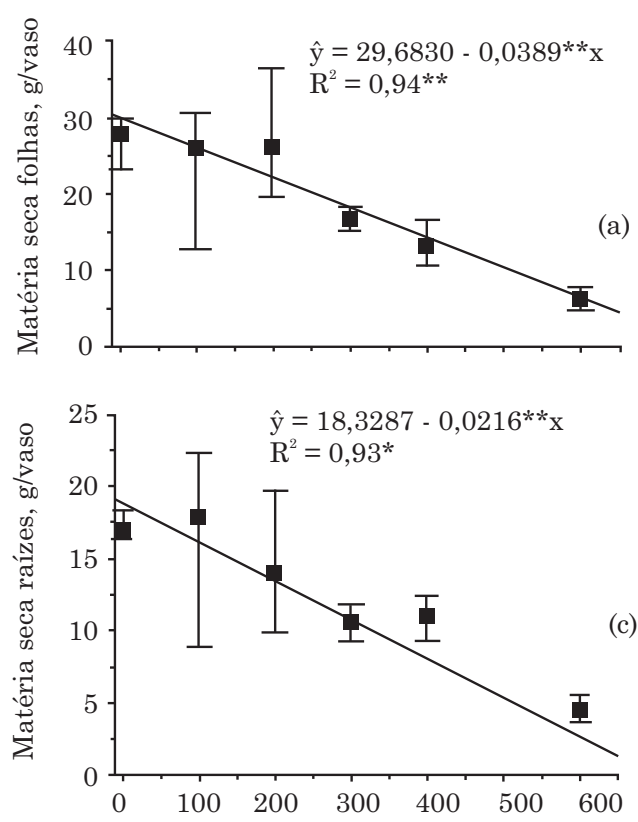

sendo realizadas quatro leituras por planta, as quais foram submetidas à emissão de luz por $10 \mathrm{~s}$.

Os espectros obtidos foram ajustados a duas curvas Gaussianas, correspondentes ao $685 \eta \mathrm{m}$ e $735 \eta \mathrm{m}$. A razão entre a intensidade da fluorescência F685/F735 (Fr/FFr) de altura de pico foi calculada a partir da curva fixada para cada uma das doses de $\mathrm{Zn}$ em solução e usada para inferir sobre o efeito do elemento no PSII, por meio do software Origin versão 6.0.

Para as análises dos pigmentos fotossintéticos, foi coletada uma amostra por planta do mesmo par de folhas utilizado na última avaliação da fluorescência de clorofila. Realizou-se a determinação dos conteúdos de clorofila $a, b$, total e carotenoides, mediante extração com acetona $80 \%$, sendo o conteúdo de carotenoides calculado pela equação de Lichtenthaler (1987).

O experimento foi conduzido em blocos ao acaso, com três repetições. A unidade experimental consistiu de um vaso contendo $6 \mathrm{~L}$ de solução nutritiva com uma planta de mamoneira. Os dados foram submetidos à ANOVA e à análise de regressão, utilizando-se o programa estatístico SAS.

\section{RESULTADOS E DISCUSSÃO}

A produção de matéria seca das plantas diminuiu linearmente com a adição de doses crescentes de Zn à solução nutritiva (Figura 1). Os efeitos visíveis da exposição a altas doses de Zn são, em geral, descritos
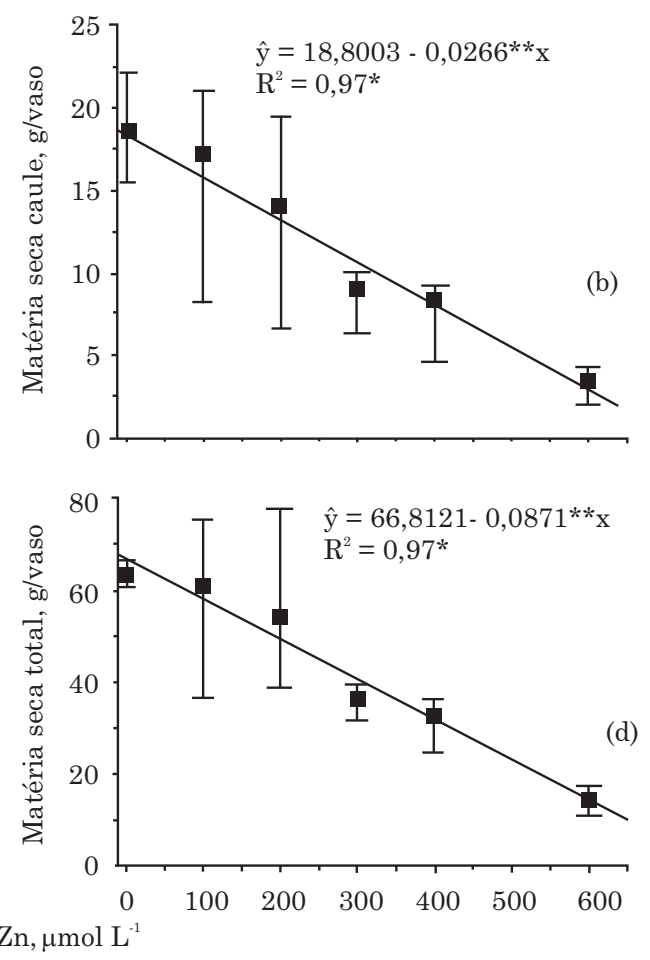

Figura 1. Matéria seca de folhas (a), caule (b), raízes (c) e total (d) de plantas de mamona cultivadas em doses de Zn em solução nutritiva. * $\mathrm{e}$ **: significativo a 5 e 1 \%, respectivamente. 
como redução severa do crescimento, da clorose e da atrofia foliar (Cunha et al., 2008). De acordo com a Agência de Proteção Ambiental do EUA (King, 1996), considera-se como tóxico o teor de metal que provoca redução de $50 \%$ do crescimento da planta, que correspondeu, neste trabalho, a $404 \mu \mathrm{mol} \mathrm{L}^{-1}$ de $\mathrm{Zn}$ (Figura 1d). No entanto, cabe salientar que a partir de $300 \mu \mathrm{mol} \mathrm{L}^{-1}$ de $\mathrm{Zn}$ as plantas apresentaram sintomas visuais de toxicidade desse elemento, caracterizados por redução do crescimento da parte aérea e escurecimento (Figura 1a,b), além de restrição do crescimento e das raízes (Figura 1c). Não foram observados efeitos deletérios de Zn até $100 \mu \mathrm{mol} \mathrm{L}^{-1}$. Isso reflete o requerimento do elemento para o metabolismo de carboidratos, a síntese de proteínas, a regulação e expressão de genes, a estrutura dos ribossomos e o seu papel como cofator em um vasto número de enzimas (Clemens et al., 2002; Broadley, 2007).

O aumento das doses de $\mathrm{Zn}$ foi acompanhado pelo acúmulo desse nutriente nas folhas, no caule e nas raízes (Figura 2), sendo o maior teor detectado nas raízes. Geralmente, a disponibilidade metabólica e a translocação de metais são limitadas pelo sequestro no vacúolo das células radiculares (Verbruggen et al., 2009). O acúmulo de metais nas raízes é um mecanismo importante que o sistema radicular pode contribuir para a tolerância de plantas a metais.

A dose $200 \mu \mathrm{mol} \mathrm{L}^{-1}$ provocou acúmulo de $417 \mathrm{mg} \mathrm{kg}^{-1}$ de $\mathrm{Zn}$ nas folhas. Teores foliares acima de 300 $\mathrm{mg} \mathrm{kg}^{-1}$ são considerados tóxicos para a maioria das plantas (Babula et al., 2008; Lin \& Aarts, 2012). No entanto, esse acúmulo foi considerado benéfico para mamoneira; apenas a partir da dose de $300 \mu \mathrm{mol} \mathrm{L}{ }^{-1}$ (900 $\mathrm{mg} \mathrm{kg}^{-1}$ nas folhas), as plantas apresentaram sintomas visuais de toxicidade e significativas reduções na produção de matéria seca (Figura 1). Isso indica o grau de tolerância da mamoneira e sua relevância para revegetação ou remediação de áreas com teores elevados de Zn no solo.

Um dos efeitos da toxicidade de Zn nas plantas foi a redução dos conteúdos de todos os nutrientes analisados (N, P, K, Ca, Mg, Cu, Fe, Mn, B, e Mo) (Quadro 1). A alteração da composição mineral tem frequentemente sido citada como importante efeito tóxico de metais em plantas (Nascimento et al., 1998; Safarzadeh et al., 2013; Lima et al., 2013). Por exemplo, Bonnet et al. (2000) verificaram reduções nos conteúdos de $\mathrm{P}, \mathrm{Ca}, \mathrm{K}, \mathrm{Mg}$, e $\mathrm{Cu}$ em folhas de azevém (Lolium perene) submetidas a doses de Zn. Esses autores ressaltaram que a deficiência desses nutrientes pode induzir a distúrbios em diversos processos metabólicos, incluindo a fotossíntese e a redução assimilatória do N. Sagardoy et al. (2009) detectaram reduções nas concentrações de N, K, Mg e Mn em todas as partes das plantas de beterraba (Beta vulgaris L.) cultivadas sob estresse de Zn.

Foi observada redução de 87 \% no conteúdo de Fe nas folhas de mamona para dose de $600 \mu \mathrm{mol} \mathrm{L}^{-1} \mathrm{de}$ Zn, em relação ao controle (Quadro 1). Esse declínio implica danos no estado fisiológico das plantas, principalmente porque o $\mathrm{Fe}$ desempenha relevantes funções metabólicas, participando de reações de oxirredução na fotossíntese, respiração mitocondrial e assimilação de N. Como 80 \% do Fe nas plantas são encontrados nos cloroplastos, sua deficiência tem sérias consequências na fotossíntese, especialmente no PSII (Hansch \& Mendel, 2009). Sagardoy et al. (2009) verificaram redução nas concentrações de pigmentos em plantas de beterraba para as doses de 50 e $100 \mu \mathrm{mol} \mathrm{L}{ }^{-1}$ de Zn em solução e efeitos severos para
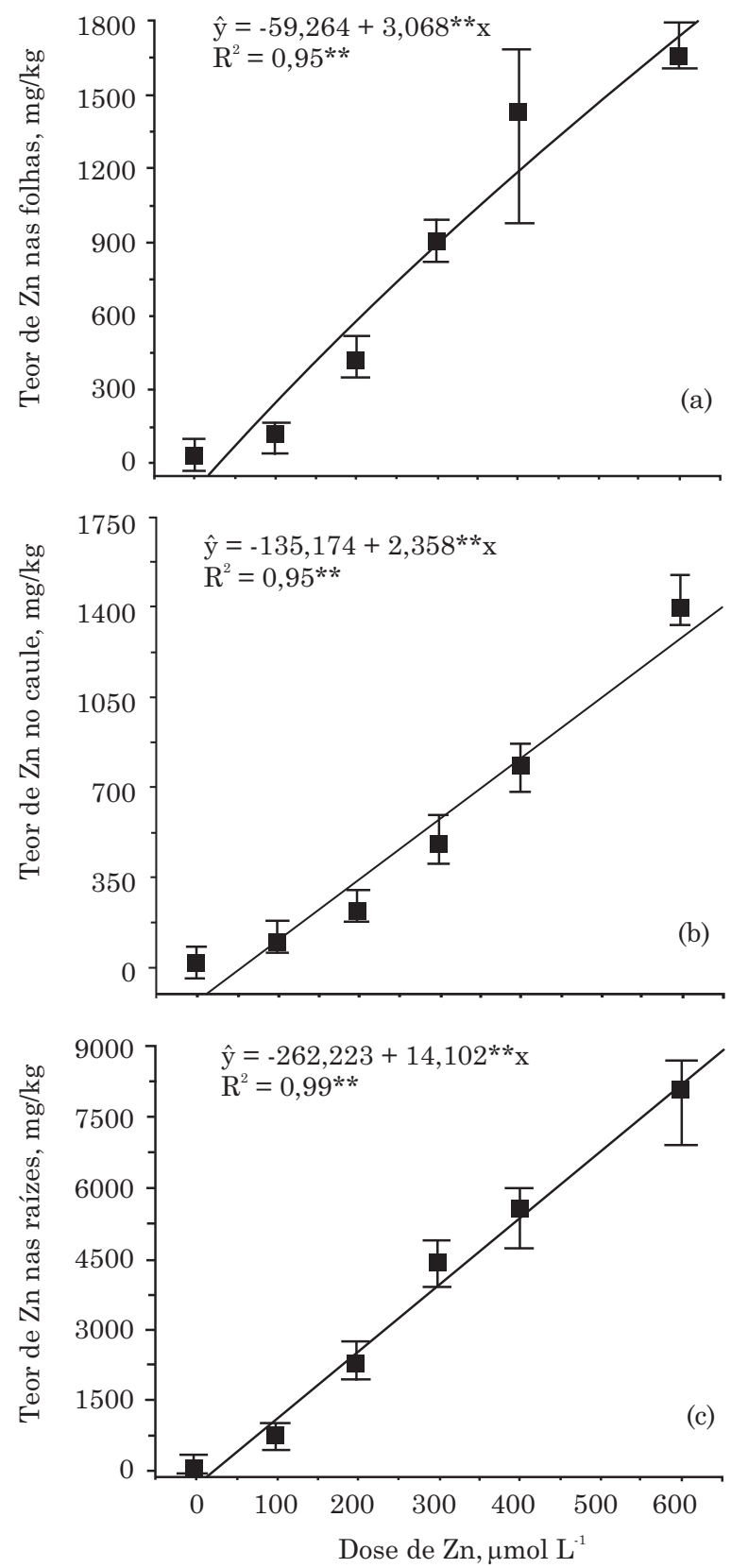

Figura 2. Teor de Zn em folhas (a), caule (b) e raízes (c) de plantas de mamona cultivadas em diferentes doses de $\mathrm{Zn}$ em solução nutritiva. * e **: significativo a 5 e $1 \%$, respectivamente. 
Quadro 1. Equações de regressão ajustadas do conteúdo de nutrientes em plantas de mamona cultivadas sob diferentes doses de Zn em solução nutritiva

\begin{tabular}{|c|c|}
\hline Variável & Equação \\
\hline Conteúdo $\mathrm{N}$ nas folhas, g/vaso & $\hat{y}=0,6239-0,0008^{* *} x ; R^{2}=0,88^{* *}$ \\
\hline Conteúdo $\mathrm{N}$ no caule, g/vaso & $\hat{y}=0,1359-0,0019^{* *} x ; R^{2}=0,96^{* *}$ \\
\hline Conteúdo $\mathrm{P}$ nas folhas, g/vaso & $\hat{y}=1,5670-0,0019^{* *} x ; R^{2}=0,93^{*}$ \\
\hline Conteúdo $\mathrm{K}$ nas folhas, g/vaso & $\hat{y}=1,1671-0,0012^{* *} x ; R^{2}=0,72^{* *}$ \\
\hline Conteúdo $\mathrm{K}$ no caule, g/vaso & $\hat{y}=0,7745-0,001^{* *} x ; R^{2}=0,98^{* *}$ \\
\hline Conteúdo $\mathrm{K}$ nas raízes, g/vaso & $\hat{y}=0,7498-0,0009^{* *} x ; R^{2}=0,87^{*}$ \\
\hline Conteúdo Ca nas folhas, g/vaso & $\hat{y}=0,933-0,0001^{*} x ; R^{2}=0,96^{*}$ \\
\hline Conteúdo Ca no caule, g/vaso & $\hat{y}=0,275-0,0004^{*} x ; R^{2}=0,97^{*}$ \\
\hline Conteúdo Ca nas raízes, g/vaso & $\hat{y}=0,0419+0,0003^{* *} x-0,5 \cdot 10^{-6 *} x^{2} ; R^{2}=0,62 *$ \\
\hline Conteúdo $\mathrm{Mg}$ nas folhas, g/vaso & $\hat{y}=0,184-0,0002^{*} x ; R^{2}=0,95^{*}$ \\
\hline Conteúdo Mg nas raízes, g/vaso & $\hat{y}=0,00001-0,01^{*} x ; R^{2}=0,92^{*}$ \\
\hline Conteúdo $\mathrm{Fe}$ nas folhas, $\mathrm{mg} / \mathrm{vaso}$ & $\hat{y}=7,205-0,011^{*} x ; R^{2}=0,81^{* *}$ \\
\hline Conteúdo Fe no caule, mg/vaso & $\hat{y}=1,229-0,005^{*} x+0,6 \cdot 10^{-5 * *} x^{2} ; R^{2}=0,97^{* *}$ \\
\hline Conteúdo $\mathrm{Cu}$ nas folhas, mg/vaso & $\hat{y}=0,4525-0,0006^{* *} x ; R^{2}=0,91^{* *}$ \\
\hline Conteúdo $\mathrm{Cu}$ no caule, $\mathrm{mg} / \mathrm{vaso}$ & $\hat{y}=0,2712-0,0004^{* *} x ; R^{2}=0,95^{* *}$ \\
\hline Conteúdo Mn nas folhas, $\mathrm{mg} /$ vaso & $\hat{y}=4,058-0,005^{*} x ; R^{2}=0,87^{*}$ \\
\hline Conteúdo Mn nas raízes, mg/vaso & $\hat{y}=5,019-0,02^{*} x+0,2 \cdot 10^{-4 *} x^{2} ; R^{2}=0,88^{*}$ \\
\hline Conteúdo B nas folhas, mg/vaso & $\hat{y}=0,1164-0,0001^{*} x ; R^{2}=0,94^{*}$ \\
\hline Conteúdo B no caule, mg/vaso & $\hat{y}=0,0274-0,3 \cdot 10^{-4 * *} x ; R^{2}=0,70^{* *}$ \\
\hline Conteúdo B nas raízes, mg/vaso & $\hat{y}=0,039-0,5 \cdot 10^{-4 *} x ; R^{2}=0,91^{*}$ \\
\hline Conteúdo Mo nas folhas, mg/vaso & $\hat{y}=0,192-0,2 \cdot 10^{-3 * x} x ; R^{2}=0,85^{*}$ \\
\hline
\end{tabular}

$* \mathrm{e}^{* *}$ : significativo a 5 e $1 \%$, respectivamente.

as plantas cultivadas em $300 \mu \mathrm{mol} \mathrm{L}-1$, resultando em deficiência quântica e, consequentemente, alterações no PSII. Assim como observado para o Fe, a redução do conteúdo de $\mathrm{Cu}, \mathrm{Mn}$, Mo também apontam inibição no estado fotossintético das plantas. Ademais, por possuir similaridade com cátions divalentes como $\mathrm{Mn}, \mathrm{Fe}$ e $\mathrm{Mg}$, o $\mathrm{Zn}$ pode competir por vários sítios bioativos, promovendo desequilíbrio em nível metabólico (Monnet et al., 2001). Uma alteração que pode ocorrer é a substituição do Mg por Zn na molécula de clorofila (Kupper et al., 1998), o que pode ter implicações sobre a capacidade fotossintética das plantas.

Os espectros apresentaram diferenças nos picos de absorção da fluorescência de clorofila (Figura 3a,b). Observou-se menor reabsorção da fluorescência nas plantas com maior estresse de Zn. De acordo com Giardi et al. (2001), a técnica da fluorescência de clorofila baseia-se em informação biológica sobre efeitos de toxicidade de contaminantes por meio da inibição na atividade do transporte de elétrons e evolução fotossintética. A técnica consegue detectar alterações no PSII em diferentes condições de estresse, por ser um fotossistema sensível a uma ampla variação de contaminantes, incluindo Zn.

Segundo Siedlecka \& Krupa (2004), a rubisco (ribulose-1,5-bifosfato carboxilase-oxigenase) é uma enzima muito importante para o ciclo de Calvin, pois participa da catalisação de reações de carboxilação e oxigenação. Em condições de estresse por metais pesados, esses podem substituir o $\mathrm{Mg}$ no centro ativo ou nas subunidades da rubisco, consequentemente bloqueando sua atividade normal e promovendo alterações no funcionamento do ciclo de Calvin. Isto resulta em inibição do transporte fotossintético de elétrons e em danos ao PSII. De acordo com MateosNaranjo et al. (2008), a exposição de plantas ao excesso de $\mathrm{Zn}$ inibe o transporte de elétrons no PSII, influenciando a fixação e assimilação de $\mathrm{CO}_{2}$, processo desencadeado por declínio da atividade da rubisco. Alterações na fluorescência são primariamente observadas no PSII, pois esse processo parece ser mais sensível a estresses ambientais (Silva et al., 2012).

A razão $\mathrm{Fr} / \mathrm{FFr}$ demonstra que as doses de $\mathrm{Zn}$ promoveram alterações na atividade fotossintética ao longo do cultivo, que se acentuaram após 18 dias de avaliação (Figura 3c). Os sintomas de toxicidade visualizados na dose $300 \mu \mathrm{mol} \mathrm{L}^{-1}$ coincidiram com o aumento na razão Fr/FFr. No entanto, o acúmulo de $\mathrm{Zn}$ nas folhas das plantas cultivadas sob doses mais elevadas apresentaram razão $\mathrm{Fr} / \mathrm{FFr}$ similares à dose de $300 \mu \mathrm{mol} \mathrm{L}{ }^{-1}$. Isso ocorreu, provavelmente, por não se observarem reduções significativas no conteúdo de clorofila acima dessa dose em solução, ou seja, o estresse causado pelo Zn no PSII foi muito semelhante para as doses de 300 e $600 \mu \mathrm{mol} \mathrm{L}^{-1}$ (Figura 3b). De acordo com Buschmann (2007), a razão Fr/FFr depende principalmente do conteúdo da clorofila e, em menor relevância, da atividade fotossintética e das características ópticas e dos arranjos celulares do tecido foliar. 
A razão $\mathrm{Fr} / \mathrm{FFr}$ (Figura 3c) indicou alteração no PSII antes dos 10 dias da adição das doses de Zn, e mesmo sem as plantas apresentarem sintomas de toxicidade. Portanto, a fluorescência de clorofila pode ser útil na detecção precoce da toxicidade por Zn em plantas, como anteriormente demonstrado para $\mathrm{Cd}$ (Silva et al., 2012), Ni (Mishra \& Gopal, 2008), Cu e $\mathrm{Hg}$ (Ventrela et al., 2009). Contudo, observou-se que as plantas apresentaram uma resistência de elevação dessa razão, acentuando-se aos 28 dias de cultivos. Notou-se também que apenas nesse período a razão $\mathrm{Fr} / \mathrm{FFr}$ foi similar para todas as doses de $\mathrm{Zn}$ adicionadas. Isso pode sugerir um forte e brusco estresse pelo $\mathrm{Zn}$ iniciado na dose $300 \mu \mathrm{mol} \mathrm{L}^{-1}$ e que se estabiliza a partir dela, sendo, portanto, menores os decréscimos nos teores de clorofila e na fluorescência de clorofila em doses mais elevadas (Figura 3b, Quadro 1). Isso pode ser ainda comprovado pela maior razão Fr/FFr ter ocorrido exatamente na maior taxa de decréscimo da matéria seca das plantas (Figura 4a), ou seja, na dose de $300 \mu \mathrm{mol} \mathrm{L}^{-1}$; para as doses maiores, essa relação se altera, relativamente, muito pouco. A fotoinibição do PSII ocorreu a partir da dose de $100 \mu \mathrm{mol} \mathrm{L}^{-1}$ de Zn (Figura 4b), embora com reduzidos efeitos na matéria seca (Figura 4a) e sem a apresentação de sintomas visuais de toxicidade.

Os conteúdos de clorofila $a$ e total (Quadro 2) apresentaram elevação com as doses de Zn, apesar do

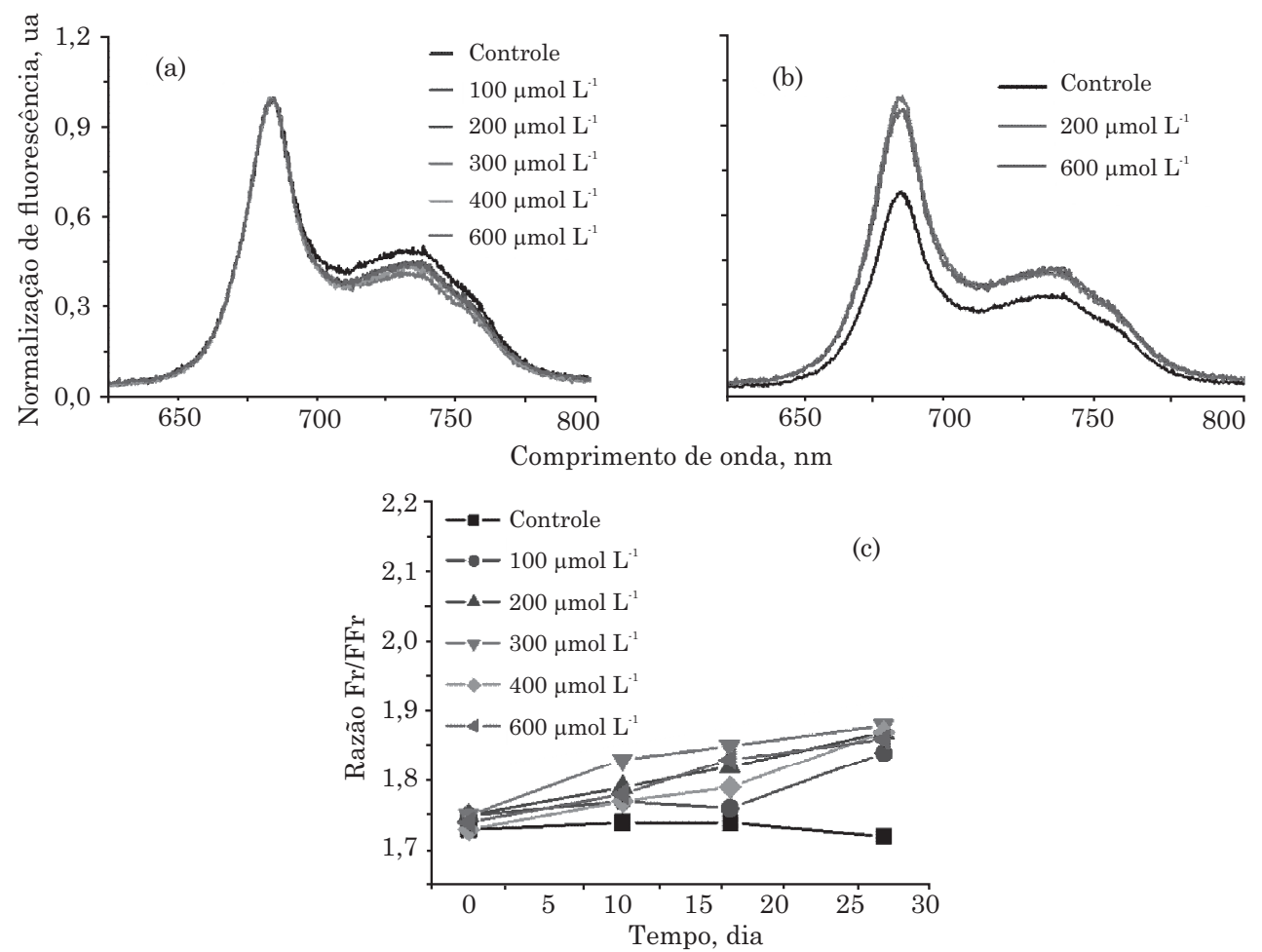

Figura 3. Espectros médios da fluorescência de clorofila em plantas de mamona cultivadas sob doses de Zn em solução nutritiva aos 28 dias, dados normalizados (a) e não normalizados (b), respectivamente. Razão dos espectros de fluorescência de clorofila em função do tempo de cultivo de plantas de mamona, referente às leituras do vermelho e vermelho distante (Fr/FFr) (c).

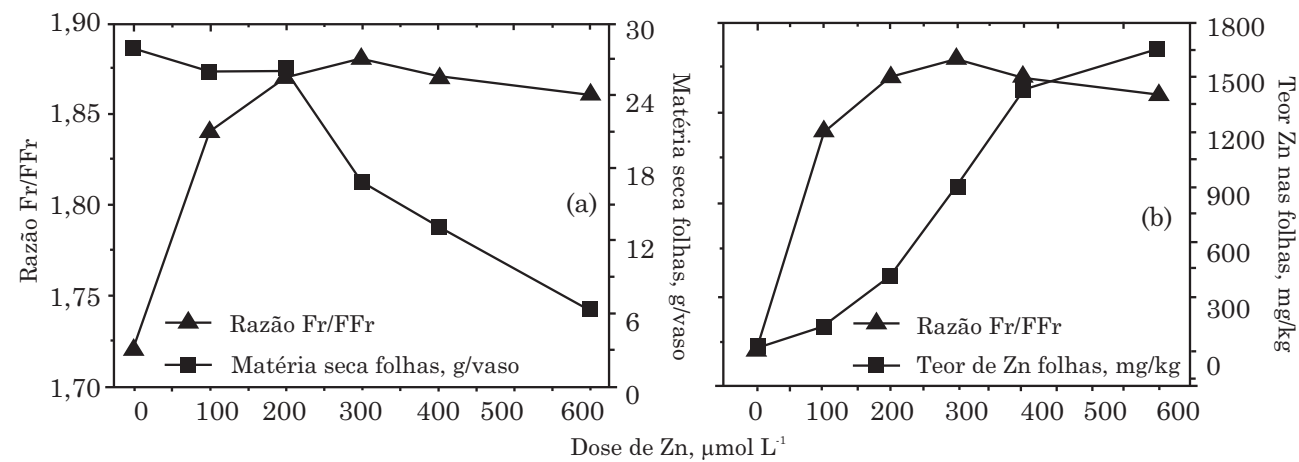

Figura 4. Razão dos espectros de fluorescência de clorofila aos 28 dias e matéria seca das folhas (a); razão dos espectros de fluorescência de clorofila aos 28 dias e conteúdo de $\mathrm{Zn}$ das folhas (b). 
Quadro 2. Equações de regressão de clorofilas em plantas de mamona cultivadas sob doses de $\mathrm{Zn}$ em solução nutritiva

\begin{tabular}{ccc}
\hline Dose de Zn & Clorofila $\boldsymbol{a}$ & Clorofila total \\
\hline$\mu \mathrm{mol} \mathrm{L}^{-1}$ & $\mathrm{mg} \mathrm{g}^{-1}$ & de matéria fresca - \\
0,380 & 0,76 & 1,114 \\
100 & 0,81 & 1,187 \\
200 & 1,13 & 1,616 \\
300 & 1,24 & 1,780 \\
400 & 1,02 & 1,460 \\
600 & 1,36 & 1,877 \\
Variável & \multicolumn{2}{c}{ Equação } \\
Clorofila $a$ & $\hat{\mathrm{y}}=0,8076+0,0009^{* *} \mathrm{x}, \mathrm{R}^{2}=0,71^{*}$ \\
Clorofila total & $\hat{\mathrm{y}}=1,1888+0,0012^{* *} \mathrm{x}, \mathrm{R}^{2}=0,68^{*}$ \\
\hline
\end{tabular}

* e **: significativo a 5 e $1 \%$, respectivamente.

efeito tóxico observado visualmente e das alterações detectadas pela razão Fr/FFr (Figura 4). Não foi verificado efeito $(p>0,05)$ para o conteúdo de clorofila $b$ e carotenoides, comportamento também encontrado por Cambrollé et al. (2013), que observaram redução da fluorescência de clorofila em condições de estresse por $\mathrm{Zn}$ em Limoniastrum monopetalum (L.) Boiss. Esses autores, no entanto, também não detectaram modificações na concentração de clorofila até 60 mmol L-1 , apenas em doses de Zn de 90 e $130 \mathrm{mmol} \mathrm{L}^{-1}$.

A baixa tolerância das plantas à toxicidade por elementos-traço pode reduzir os teores de clorofilas e carotenoides (Joshi \& Mohanty, 2004; Maurya et al., 2008; Shi \& Cai, 2009). Assim, pode-se mais uma vez inferir a tolerância da mamona à toxicidade de Zn, visto que os pigmentos avaliados são importantes indicadores de alterações fotossintéticas.

\section{CONCLUSÕES}

1. A medida da fluorescência de clorofila indicou alterações temporais promovidas pelo acúmulo de $\mathrm{Zn}$ nas plantas e evidenciou-se útil na detecção precoce da toxicidade do elemento em plantas de mamona.

2. A mamona apresentou relativa tolerância à toxicidade por $\mathrm{Zn}$, não demonstrando efeitos deletérios aos pigmentos fotossintéticos, apesar do declínio no estado nutricional das plantas. Considerando essa tolerância a doses elevadas do metal, essa espécie pode ser alternativa atraente para fitoestabilização de áreas contaminadas, com adicional vantagem para produção de bioenergia.

\section{AGRADECIMENTOS}

A primeira autora agradece à Facepe /CAPES, pela concessão da bolsa de estudos durante o doutorado; e ao Programa de Pós-Graduação em Ciência do Solo da UFRPE. Os autores agradecem ao Prof. Artur Gouveia-Neto (UFRPE) pela cessão do emissor LED e ao Prof. Airon Silva (UFS) pela ajuda na condução do experimento.

\section{LITERATURA CITADA}

BABULA, P.; ADAM, V.; OPATRILOVA, R.; ZEHNALEK, J.; HAVEL, L. \& KIZEK, R. Uncommon heavy metals, metalloids and their plant toxicity: A review. Environ. Chem. Lett., 6:189-213, 2008.

BONNET, M.; CAMARES, O. \& VEISSEIRE, P. Effect of zinc and influence of Acremonium lolii on growth parameters, chlorophyll $a$ fluorescence and antioxidant enzyme activities of ryegrass (Lolium perenne L. cv Apollo). J. Exp. Bot., 51:945-953, 2000.

BROADLEY, M.R. Zinc in plants. New Phytol., 173:677-702, 2007.

BUSCHMANN, C. Variability and application of the chlorophyll fluorescence emission ratio red/far-red of leave. Photosynt. Res., 92:261-271, 2007.

CAMBROLLÉ, J.; MANCILLA-LEYTON, J.M.; MUNOZVALLES, S.; FIGUEROA-LUQUE, E.; LUQUE, T. \& FIGUEROA, M.E. Evaluation of zinc tolerance and accumulation potential of the coastal shrub Limoniastrum monopetalum (L.) Boiss. Environ. Exp. Bot., 85:50-57, 2013.

CHERIF, J.; MEDIOUNI, C.; AMMAR, W.B. \& JEMAL, F. Interactions of zinc and cadmium toxicity in their effects on growth and in antioxidative systems in tomato plants (Solanum lycopersicum). J. Environ. Sci., 23:837-844, 2011.

CLEMENS, S.; PALMGREN, M.G. \& KRAMER, U. A long way ahead: Understanding and engineering plant metal accumulation. Trends Plant Sci., 7:309-315, 2002.

CORCOLL, N.; BONET, B.; LEIRA, M. \& GUASCH, H. Chl-a fluorescence parameters as biomarkers of metal toxicity in fluvial biofilms: an experimental study. Hydrobiologia, 673:119-136, 2011.

CUNHA, K.C.V.; NASCIMENTO, C.W.A.; PIMENTEL, R.M.M.; ACCIOLY, M.A. \& SILVA, A.J. Disponibilidade, acúmulo e toxidez de cádmio e zinco cultivado em solo contaminado. R. Bras. Ci. Solo, 32:1319-1328, 2008.

GADJEV, I.; STONE, J.M. \& GECHEV, T.S. Programmed cell death in plants: new insights into redox regulation and the role of hydrogen peroxide. Intern. Rev. Cell Molec. Biol., 270:87-144, 2008.

GIARDI, M.T.; KOBLÍZEK, M. \& MASOJÍDEK, J. Photosystem II-based biosensors for the detection of pollutants. Biosens. Bioelectron., 16:1027-1033, 2001.

HANSCH, R. \& MENDEL, R.R. Physiological functions of mineral micronutrients $(\mathrm{Cu}, \mathrm{Zn}, \mathrm{Mn}, \mathrm{Fe}, \mathrm{Ni}, \mathrm{Mo}, \mathrm{B}, \mathrm{Cl})$. Curr. Opin. Plant Biol., 12:259-266, 2009.

HOAGLAND, D.R. \& ARNON, D.L. The water culture methods for growing plants without soil. Berkeley, University of California, 1950. 32p. (Circular, 347) 
JOSHI, M.K. \& MOHANTY, P. Chlorophyll a fluorescence as a probe of heavy metal ion toxicity in plants. In: PAPAGEORGIOU, G. C. \& GOVINDJEE, eds. Advances in photosynthesis and respiration, chlorophyll a fluorescence, Chlorophyll a Fluorescence: A signature of photosynthesis. Dordrecht, Springer, 2004. p.637-661.

KING, L.D. Soil heavy metals. In: ALVAREZ V., V. H.; FONTES, L. E. \& FONTES, M. P., eds. Os solos nos grandes domínios morfoclimáticos do Brasil e o desenvolvimento sustentado. Viçosa, MG, Sociedade Brasileira de Ciência do Solo/Universidade Federal de Viçosa, 1996. p.823-836.

KUPPER, H.; KUPPER, F. \& SPILLER, M. In situ detection of heavy metal substituted chlorophylls in water plants. Photosynthetica, 58:123-133, 1998.

LICHTENTHALER H.K. Chlorophylls and carotenoids: Pigments of photosynthetic biomembranes. In: PACKER, L. \& DOUCE, R., eds. Methods in enzymology. NewYork, Academic Press, 1987. p.350382 .

LIMA, F.S.; NASCIMENTO, C.W.A.; ACCIOLY, A.M.A.; SOUSA, C.S. \& CUNHA FILHO, F.F. Bioconcentração de chumbo e micronutrientes em hortaliças cultivadas em solo contaminado. R. Ci. Agron., 44:234-241, 2013.

LIN, Y. \& AARTS, M.G.M. The molecular mechanism of zinc and cadmium stress response in plants. Cell. Molec. Life Sci., 69:3187-3206, 2012.

MATEOS-NARANJO, E.; REDONDO-GÓMEZ, S.; CAMBROLLÉ, J.; LUQUE, T. \& FIGUEROA, M.E. Growth and photosynthetic responses to zinc stress of an invasive cordgrass Spartina densiflora. Plant Biol., 10:754-762, 2008.

MAURYA, R.; PRASAD, S. M. \& GOPAL, R. LIF technique offers the potential for the detection of cadmiuminduced alteration in photosynthetic activities of Zea mays L. J. Photochem. Photobiol. C: Photochem. Rev., 9:29-35, 2008.

MISHRA, K. B. \& GOPAL, R. Detection of nickel-induced stress using laser induced fluorescence signatures from leaves of wheat seedlings. Intern. J. Remote Sens., 29:157-173, 2008.

MONNET, F.; VAILLANT, N.; VERNAY, P.; COUDRET, A.; SALLANON, H. \& HITMI, A. Relationship between PSII activity $\mathrm{CO}_{2}$ fixation, and $\mathrm{Zn}, \mathrm{Mn}$ and $\mathrm{Mg}$ contents of Lolium perenne under zinc stress. J. Plant Physiol., 158:1137-1144, 2001.
NASCIMENTO, C.W.A.; FONTES, R.L.F. \& NEVES, J.C.L. Mineral composition of two Brazilian corn cultivars as a function of cadmium in the nutrient solution. J. Plant Nutr., 21:2369-2379, 1998.

SAFARZADEH, S.; RONAGHI, A. \& KARIMIAN, N. Effect of cadmium toxicity on micronutrient concentration, uptake and partitioning in seven rice cultivars. Arch. Agron. Soil Sci., 59:231-245, 2013.

SAGARDOY, R.; MORALES, F; LÓPEZ-MILLÁN, A-F; ABADÍA, A. \& ABADÍA, J. Effects of zinc toxicity on sugar beet (Beta vulgaris L.) plants grown in hydroponics. Plant Biol., 11:339-350, 2009.

SHABALA, S. Metal cations in $\mathrm{CO}_{2}$ assimilation and conversion by plants. J. Miner. Met. Mater. Soc., 61:28-34, 2009.

SHI, G. \& CAI, Q. Cadmium tolerance and accumulation in eight potential energy crops. Biotechem. Adv., 27:555$561,2009$.

SIEDLECKA, A. \& KRUPA, Z. Rubisco activity maintenance in environmental stress conditions-how many strategies. Cell. Molec. Biol. Lett., 9:56-57, 2004.

SILVA, J.P.S.; NASCIMENTO, C.W.A.; BIONDI, C.M. \& CUNHA, K.P.V. Heavy metals in soils and plants in mango orchards in Petrolina, Pernambuco, Brazil. R. Bras. Ci. Solo, 36:1343-1354, 2012.

SILVA, A.J.; NASCIMENTO, C.W.A.; GOUVEIA-NETO, A.S. \& SILVA-JR, E.A. LED-induced chlorophyll fluorescence spectral analysis for the early detection and monitoring of cadmium toxicity in maize plants. Water Air Soil Pollut., 223:3527-3533, 2012.

SOARES, C.R.F.S.; ACCIOLY, A.M.A.; MARQUES, T.C.L.L.S.; SIQUEIRA, M.J.O. \& MOREIRA, F.M.S. Acúmulo e distribuição de metais pesados nas raízes, caule e folhas de mudas de árvores em solo contaminado por rejeitos de indústria de zinco. R. Bras. Fisiol. Veg., 13:302-315, 2001.

UNITED STATES ENVIRONMENTAL PROTECTION AGENCY - USEPA. Microwave assisted acid digestion of sediments, sludges, soils, and oils. Method 3051A, 1998. CD-ROM

VENTRELA, A.; CATUCCI, L.; PILETSKA, E.; PILETSKY, S. \& AGOSTIANO, A. Interactions between heavy metals and photosynthetic materials studied by optical techniques. Bioelectrochemistry, 77:19-25, 2009.

VERBRUGGEN, N.; HERMANS, C. \& SCHAT, H. Molecular mechanisms of metal hyperaccumulation in plants. New Phytol., 181:759-776, 2009. 